NBER WORKING PAPER SERIES

\title{
WHY DO INVENTORIES RISE WHEN DEMAND FALLS IN HOUSING AND OTHER MARKETS?
}

Edward P. Lazear

Working Paper 15878

http://www.nber.org/papers/w15878

\author{
NATIONAL BUREAU OF ECONOMIC RESEARCH \\ 1050 Massachusetts Avenue \\ Cambridge, MA 02138 \\ April 2010
}

Data provided by the National Association of Realtors is gratefully acknowledged. I thank Gary Becker, Peter DeMarzo, Darrell Duffie, Dirk Jenter, David Kreps, Donald Marron, Kevin M. Murphy, Jesse Shapiro, Kathryn Shaw, Robert Shimer, and Andy Skrzypacz for useful comments. Nicholas Obradovich provided excellent research assistance. The views expressed herein are those of the author and do not necessarily reflect the views of the National Bureau of Economic Research.

NBER working papers are circulated for discussion and comment purposes. They have not been peerreviewed or been subject to the review by the NBER Board of Directors that accompanies official NBER publications.

(C) 2010 by Edward P. Lazear. All rights reserved. Short sections of text, not to exceed two paragraphs, may be quoted without explicit permission provided that full credit, including $\odot$ notice, is given to the source. 
Why Should Inventories Rise When Demand Falls in Housing and Other Markets?

Edward P. Lazear

NBER Working Paper No. 15878

April 2010, Revised February 2011

JEL No. D0

\begin{abstract}
$\underline{\text { ABSTRACT }}$
Inventories and price changes are correlated. The inverse relation is most obvious in housing where inventories build in low demand markets and shrink in high demand markets. This is a puzzle. If sellers and buyers had symmetric views of the world, one would think that sellers would lower their reservation value at the same rate that buyers lower their offer price. Because there is heterogeneity among buyers in the valuation of a given house and because houses are not homogeneous, sellers set prices strategically. When demand falls, it is optimal for sellers to lower their prices but not by enough to keep the probability of sale constant. As a result, inventories grow. This is consistent with the most basic theory of monopoly pricing and requires no irrationality on the part of sellers or buyers. Furthermore, a distinguishing feature of this theory is that it implies that the negative correlation between inventories and price changes should not be observed in perfectly competitive markets where goods are homogeneous, e.g., stock or commodity markets.
\end{abstract}

Edward P. Lazear

Graduate School of Business

and Hoover Institution

Stanford University

Stanford, CA 94305

and NBER

lazear@stanford.edu 
Housing inventories rise in declining markets, when prices are falling. This is a puzzle. If buyers and sellers had symmetric views of the world, sellers should lower their selling price by the same amount as buyers lower their offers, or so it would seem. Given symmetry among buyers and sellers, there would be no change in inventories. An inventory in housing reflects a failure to sell. ${ }^{1}$ What is the source of asymmetry that induces sellers to lower prices by less than the amount necessary to clear the market when demand declines?

I suggest the following answer. Sellers who face a non-degenerate distribution of offer values from potential buyers choose a price at which to sell. When demand for their good, say their house, falls, they adjust prices optimally. But, as will be shown, optimal pricing implies that a decline in demand is met by a reduction in price that is insufficient to keep the probability of sale constant. Because there is heterogeneity among buyers, analogous to the downward sloping demand that a monopolist faces, it pays to continue to price at a relatively high level in the hope that a buyer will come along who values the house enough to pay the high selling price. The seller understands that unwillingness to lower the price by a larger amount results in a greater chance that the house will go unsold, but accepts that risk in order to receive a higher price in the instances where the house does sell. Sellers stick to high prices because they are hoping that the buyer who values their house more than others will happen along. The reasoning is analogous to that of a monopolistic firm that lowers product price in the face of declining demand. Even though the optimal price falls when demand declines, it does not fall by enough to keep the quantity sold

\footnotetext{
${ }^{1}$ In some sense, that is tautologically true of all inventory because at a sufficiently low price, the good or input would have been sold. But inventories of sandwiches that sit in a lunch place at $11 \mathrm{am}$ are probably best thought about differently from houses left on the market because the price was too high to induce someone to buy. Below, a distinction is made between "strategic inventory," that exists because of optimal pricing in an environment of stochastic demand, and "accidental inventory" that results because of randomness in supply because of unpredictability in the production or distribution process.
} 
constant. Because the seller can choose price, he generally takes some of the hit from the decline in demand in the form of a price decline and some in the form of a quantity decline. The housing market example is similar, only in a stochastic environment where the probability of sale corresponds to the quantity sold in a deterministic world. ${ }^{2}$

Not all markets exhibit this behavior. Stock markets provide a counterexample. When demand for a stock falls, say, because the firm is viewed to have lower future earnings, prices fall accordingly, and the market clears. There are no unsold shares remaining at the end of the day.

The difference in markets has to do with heterogeneity. In stock markets, each share is identical and no one seller has any monopoly power to set price for the shares that he owns. Sellers of stock are price takers because the distribution of offers for their shares is degenerate at the market price. In housing markets, each house and potential buyer is idiosyncratic, implying that there is a non-degenerate distribution of offers for a house and imperfect competition on the supply side that prevents all houses from being priced identically, attribute adjusted. ${ }^{3}$

Others have examined pricing and sale probability, especially in housing. Case (2008) provides an excellent overview of the history of housing prices and discusses housing price stickiness in downturns and its potential causes. Inventories are a consequence of sticky prices and Case addresses inventory behavior and its relation to prices. ${ }^{4}$

\footnotetext{
${ }^{2}$ There remains the issue of whether the "marginal cost" curve falls with demand. Normally the answer is no, and later, it will be shown that the same negative answer is appropriate here. ${ }^{3}$ See Rosen's (1974) classic paper on how prices adjust to reflect differences in attributes.

${ }^{4}$ A nice analysis of different kinds of sellers is provided by Albrecht, Anderson, Smith and Vroman (2007). They obtain a relation of time-on-market to price movements because in markets characterized by long market times, the proportion of motivated sellers, who will accept a lower price, rises. Zuehike (1987) also analyzes motivated sellers in a different context and finds that the seller has a stronger incentive to adopt diminishing reservation price if the house is vacant rather than occupied. Asabere and Huffman (1993) emphasize the reverse pattern. For a given seller, in a model with repeat search and heterogeneity, the longer a seller is willing to wait, the higher the
} 


\section{Other explanations}

Rational pricing is the mechanism through which the explanation operates, but there are other potential stories. The first is that this is straight supply and demand that emphasizes causation in the opposite direction. When there is a shock that creates excess supply, prices fall and excess supply means that inventories rise. The inventory is itself evidence of excess supply so when inventories are high, prices fall. There are three problems with this explanation.

First, it remains necessary to explain how the inventories accumulated. An increase in supply or decrease in demand does not by itself mean that inventories rise. If the market cleared perfectly and instantly, prices would fall, but there would be no increase in inventory associated with excess supply. The increase in inventory may be a result of pricing choices that do not clear the market, which implies that a strategic pricing element may be buried in the existence of inventories. $^{5}$

Second, there are strong empirical findings that make implausible the excess supply view without some strategic pricing. In the most recent housing market collapse, the inventories to sales ratio reached a low in early 2005 at inventories equal to slightly under four months of sales. Almost five years later, the inventory to sales ratio was still over double the levels seen then. Without some stickiness in prices or change in technology that makes larger inventories optimal, it is very difficult to explain so much persistence in excess supply. The same inventory persistence, albeit for shorter periods, is seen in the auto industry for new car inventories, even though new car

expected price received. Related, Anglin, Rutherford and Springer (2003) provide evidence that the higher the asking price, the longer is time on the market.

${ }^{5}$ Indeed, Case and Shiller (1989a) examine housing price behavior. Much of their focus is on causation running from inventories to prices as a result of excess supply. Still, this pushes the question back one level. Why was there a failure to sell that allowed inventories to build? Why did prices fail to adjust to clear the market? 
models change each year and there is strong pressure to eliminate inventories before the model change.

Third, strategic pricing is relevant when sellers have monopoly power only. The inventories-cause-price-declines explanation should be relevant in competitive and monopolistic industries alike whereas the demand-declines-cause-inventories explanation is valid only in industries with monopoly power. As is shown formally below, the model implies that the correlation between inventories and price changes should be stronger in markets with more heterogeneity and monopoly power. This is testable. Thus, stock markets, where sellers are price takers should not see correlations between inventories and prices, whereas housing markets, where sellers are price setters, should see a negative correlation between price changes and inventories.

A completely different explanation relies on psychological factors. Sellers may be unwilling to lower their prices, say, because they are reluctant to accept less than they paid for the house. This seems tantamount to assuming the answer. Prices are not lowered enough because sellers are unwilling to lower them enough. But there are some intellectual underpinnings to this view, based on laboratory experiment data. Tversky and Kahneman's (1991) notions of loss aversion is a more technical and general concept that fits this rationale. Although this surely has a ring of truth to it, there remain problems with adopting loss aversion as explanation. ${ }^{6}$

First, sellers sometimes do take losses, accepting less than they paid for the house. For example, during January, 2010 in Sacramento, California, over one-fifth of the house sales were at levels that not only fell short of the purchase price, but were short of the amount owed on the bank

\footnotetext{
${ }^{6}$ Genesove and Mayer (2001) argue that sellers' aversion to realizing losses makes them resist lowering prices and helps explain the positive price-volume correlation in real estate markets. A similar theme is pushed for assets in Odean (1998). Related, Case and Shiller (1989b) reject the view that housing prices are consistent with an efficient markets view.
} 
loans. ${ }^{7}$ When does a seller's reluctance result in a failure to sell and when does it result in a final grudging acceptance of a lower price?

Second, there are well-tested psychological theories that imply the opposite behavior by sellers. Specifically, panic selling that results because all rush to the door in a declining market is the opposite phenomenon of reluctance to accept a lower price. ${ }^{8}$ Rather than holding on to a given price and hoping to sell, the seller wants to get rid of the merchandise "at any price," to avoid being the last person standing in a game of musical chairs. ${ }^{9}$ Indeed, the decline in the S\&P 500 from over 14,000 in October, 2007 to around 6,500 in March, 2009, occurred at the same time that house prices were falling, but falling too slowly to keep inventories constant. Why were some, and sometimes the same, individuals who were reluctant to sell their houses at low prices so anxious to sell their stocks at huge losses just to get out of the market? Why did not fear of future declines in housing prices induce sellers to dump their houses quickly, accepting low prices and driving inventories down? A good theory must be able to determine when one behavior holds and when the other behavior holds, otherwise it is neither refutable nor testable.

In this vein, it might be argued that houses are different from stock and that "endowment effects" are stronger for houses than for stock. Perhaps, but is there evidence that supports this,

7 Source: Sacramento Association of Realtors (http://www.sacrealtor.org/publicaffairs/statistics.html)

${ }^{8}$ See Shiller (2006) and Akerlof and Schiller (2009), which suggests that markets act in capricious ways because of underlying psychological patterns. Their approach seems better suited to explaining excessive volatility than to explaining a price-stickiness bias in one direction or another, necessary for the correlation between inventories and demand.

${ }_{9}^{9}$ Among the early theoretical contributions are Bikhchandani, Hierschleifer (1992), Banerjee (1992), and Bulow and Klemperer (1994). An early empirical application involving mutual funds and trading is Grinblatt, M., S. Titman, and R. Wermers (1995). 
and if so, how does this extend to other goods? Is a car more like a house or more like a stock? What about gold? How about a gold watch? ${ }^{10}$

By contrast, the theory offered in this paper gives a clear prediction that housing markets will exhibit increasing inventories with falling prices, but that stock markets will not behave in this way. The key is heterogeneity that results in a non-degenerate offer distribution for the individual seller. Because stock markets are competitive and no monopoly power exists, there is no pricing strategy that allows for selecting a high price and low probability of sale. With housing, heterogeneity in valuation by potential buyers for a given house creates the equivalent of a downward sloping demand curve faced by a monopolist. Given the downward slope, the reluctance to allow prices to fall enough to keep the probability of sale and therefore inventories the same is a natural consequence of optimal pricing.

The argument is made in two stages. First, it is shown that a seller with a given reservation value, who is completely aware of a decline in demand, does not lower his price enough to keep the probability of sale constant. Second, it is shown that sellers do not reduce their reservation values when demand falls by enough to keep the probability of sale constant.

Motivating Data

Some basic numbers from the housing market help motivate the theory that comes below. Using data from the National Association of Realtors, the Census Bureau, and the Department of Housing and Urban Development (HUD), the inventory-to-sales ratio for all houses, existing and

\footnotetext{
${ }^{10}$ Even for houses, the endowment effect story is incomplete. When demand is increasing, sellers let go of their houses very quickly, sometimes running auctions or allowing their houses to be sold before they are even on the market. Why does the endowment effect not bite strongly on the upside, keeping sellers from letting go of their houses?
} 
new, was constructed. ${ }^{11}$ The price of houses, adjusted for quality by examining repeat sales, is reported in the FHFA (formerly OFHEO) and S\&P Case Shiller indexes. ${ }^{12}$ The relation of house (new and existing) inventory-to-sales ratio with changes in housing prices (FHFA) is shown in Figure 1. ${ }^{13}$

Figure 1

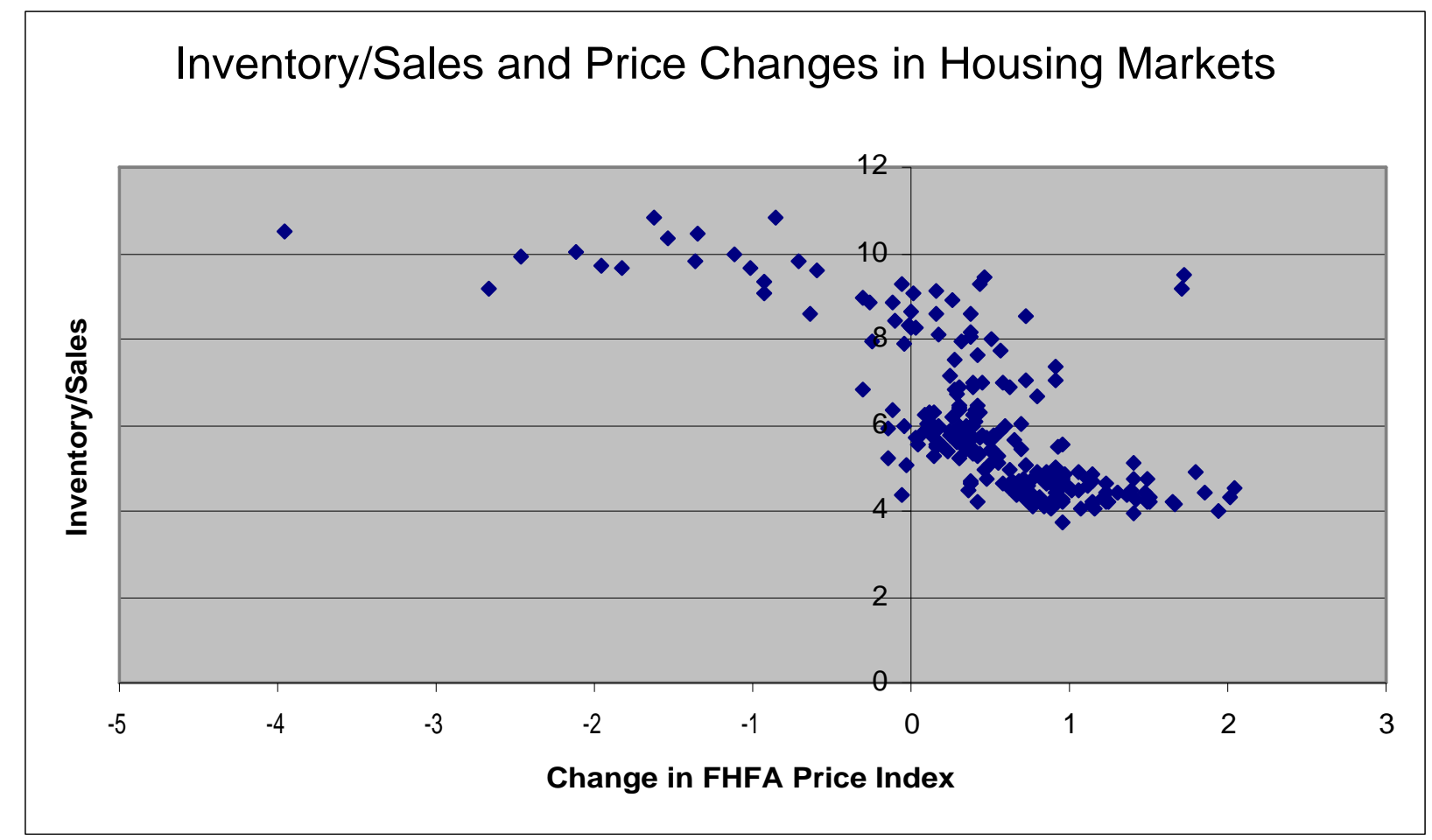

${ }^{11}$ The National Association of Realtors provided data on existing home sales and inventories, the Census Bureau reports new home sales and inventories, and the Dept. of Housing and Urban Development gives the FHFA price index.

${ }^{12}$ Each price index has its strengths and weaknesses. The FHFA index covers the entire country, whereas S\&P Case Shiller is limited to selected metropolitan areas. But the FHFA reports data for a subset of houses, namely those that are in the "conforming loan" category, which leaves out the highest priced houses.

${ }^{13}$ The level of inventory-to-sales ratio (rather than changes in that ratio) is used because the lag structure is uncertain and because the relation is not causal. The presumption is that the level of inventory-to-sales is a better indicator of changes in demand over the relevant period than is, say, the monthly change in inventory-to-sales ratio simply because the noise in the monthly inventory change data is too great. Also, because the expected duration to sale is more than one month (and variable with demand), this month's inventory change is not necessarily related to this month's price change. However, a check of changes on changes reveals a strong negative relationship also, which becomes weakly negative and insignificant in Cochrane-Orcutt regressions. 
The diagram shows that the relationship is negative. Inventories are highest when housing prices are declining most rapidly. The simple correlations are reported in Table 1. They reveal a negative relation of inventory/sales to change in housing prices.

Table 1

Correlation of Inventory-to-Sales Ratio with Price Changes

\begin{tabular}{|c|c|c|}
\hline & Change in FHFA & Change in S\&P Case Shiller \\
\hline Inventory/Sales & -0.73 & -0.85 \\
\hline
\end{tabular}

Monthly data from 1991. 220 observations.

Model

The model is general and relates potentially to a large variety of goods, namely those over which the seller has some monopoly power. For concreteness, and to fit perhaps the most important case, the discussion is cast in terms of houses. The essence is to model that potential buyers do not all attach the same value to a house. The seller sets a reservation price knowing that some buyers may view that price well below their valuation, whereas others might view it as excessive. In actual housing purchases, bargaining is part of the story, but this model abstracts from that by assuming that the seller's actual reservation price is the one posted, rather than some higher price as an opening gambit. ${ }^{14,15}$

${ }^{14}$ Fuchs and Skrypacz (2010) obtain a relation between time on the market and prices by focusing on the amount of delay in bargaining, which results when new traders appear or other outside options become available.

${ }^{15}$ There is a literature that examines list price and sale probabilities, both theoretical and empirical. For example, Arnold (1999) explores a model where buyers use asking price as information and then make a buy decision after touring the house. See also Chen and Rosenthal (1996) for another model of price setting with search, where inspection provides information with a mention of housing markets. Glower, Haurin and Hendershott (1998) examine the influence of listing price on time to sale and find no relationship. Merlo and Ortalo-Magne (2004) find different behavior 
Consider a single period decision for the seller of a given house. The buyers' valuations are given by $V \sim g(V)$. For simplicity, assume the seller encounters one buyer whose valuation is drawn from that distribution.

The probability of a sale is the probability that the seller encounters a buyer whose valuation exceeds selling price $R$ and the seller's reservation value $S$, the latter being redundant because $R$ will always be set at least as high as $S$. Thus, the probability of a sale is given by 1$G(R)$ where $G(V)$ is the distribution function of density $g(V)$. The seller's problem is then to maximize

$$
\text { Value of the House }=R[1-G(R)]+S G(R)
$$

The first-order condition is

$$
\frac{\partial}{\partial R}=1-G(R)+g(R)(S-R)=0
$$

or

$$
R=S+\frac{1-G(R)}{g(R)}
$$

The second-order condition is

$$
\frac{\partial^{2}}{\partial R^{2}}=-2 g(R)-g^{\prime}(R)(R-S)
$$

which is not necessarily negative.

using English data, where listing price is found to influence the arrival of offers, and therefore the rate of sale. Yavas and Yang (1995) find that the effect of listing price depends on the overall cost of the home (high, middle or low). Of course, a key issue here is how list price is related endogenously to market conditions and the relation of list to reservation price and sale price. 
In this framework, inventories are unsold houses at the end of the period. The size of the expected inventory in a market then is the number of houses on the market times the probability that each of those houses goes unsold. The probability that a house does not sell is simply the probability that a seller encounters a buyer whose valuation lies below the reservation price $R .^{16}$

\section{Sellers Do Not Lower Price Enough to Keep the Probability of Sale Constant}

The primary issue is determining the effect of a decline in market demand on price, $R$, and inventories, here represented by the probability that a house does not sell, $G(R)$. Represent a decline in demand as a shift in the valuation that potential buyers place on the house. Let $H(V)$ represent a distribution that is first-order stochastically dominated by $G(V)$, so that $H(V)>G(V) \forall$ $V$.

Denote $R_{i}$, where $i=G, H$, the price that the seller chooses for the distribution $G$ or $H$. Then from (2)

$$
R_{G}>R_{H}
$$

iff

$$
\frac{1-G\left(R_{G}\right)}{g\left(R_{G}\right)}>\frac{1-H\left(R_{H}\right)}{h\left(R_{H}\right)}
$$

Condition (3) holds for all distributions where $g(V) \leq h(V)$ and where $g^{\prime}(V), h^{\prime}(V)<0$ (proof in Appendix A). This condition is somewhat restrictive and even when met, is informative only of price movements, not of the correlation between price movements and sale probabilities.

\footnotetext{
${ }^{16}$ For now, take the number of houses on the market as given. In a later section, variations in number of houses on the market are explored. That effect is likely to work in the opposite direction with fewer houses on the market during periods of declining demand.
} 
Consequently, it is instructive to consider specific distributions for which condition (3) holds and when the probability of sale declines with falling $R$ as well.

Uniform: Let $V \sim U[a, a+d]$ so that $g(V)=1 / d$ and $G(V)=\frac{V-a}{d}$. Substitution into (2) yields ${ }^{17}$

$$
R=\frac{S+a+d}{2}
$$

It is immediate that $R$ rises in $a$ and $d$. A shift in market demand reflected in a leftward shift of the offer distribution can be characterized as a decline in $a$. We can then think of $H(V)$ above as the distribution with a lower value of $a$. Furthermore, the probability of no sale is given by

$$
\text { Probability no sale }=G(R)=\frac{1}{2}-\frac{S-a}{2 d}
$$

so the probability of no sale decreases in $a$. As demand declines, reflected in a leftward shift of the offer distribution where $a$ falls, price falls and the sale probability falls. This is consistent with the primary empirical result to be explained - inventories vary inversely with price changes.

Normal: Let $V$ be distributed normally with mean $\lambda \mu$ (with $\mu>0)$ and standard deviation $\lambda \sigma$, where $\lambda$ is a scaling parameter. Let $S$ be sufficiently low so that the normal is an almost perfect approximation of the truncated normal that results for the normal above $S$. Let the reservation value also be $\lambda S$. Then it is easy to show numerically that

$$
\frac{\partial R}{\partial \lambda}=\lambda
$$

\footnotetext{
${ }^{17}$ The second-order condition for a maximum is satisfied because $g^{\prime}(R)=0$.
} 
That is, if the normal is just scaled up, the optimal price adjusts correspondingly and the probability of no sale remains unchanged.

A decline in demand can be characterized, as in the case of the uniform above, as a leftward shift in the offer distribution, i.e., for a given $\sigma$ and $\lambda, \mu$ falls. Again, numerical analysis reveals that

$$
\frac{\partial \operatorname{Pr} \text { no sale }}{\partial \mu}<0
$$

and that

$$
\frac{\partial R}{\partial \mu}>0
$$

For example, when $S=20, \mu=100, \sigma=20, R=78$ and the probability of no sale $=0.18$. When $\mu$ falls to $80, R$ falls to 67 , the probability of no sale rises to 0.25 . The pattern is monotonic. ${ }^{18}$

Once again, the general empirical phenomenon holds. As the mean of the offer distribution declines, reflecting a decrease in demand, prices fall but the probability that the good remains unsold rises.

Gamma: Let $V$ be distributed as gamma with density function given by

$$
g(V ; \alpha)=\frac{V^{\alpha-1} e^{-V}}{\Gamma(\alpha)}
$$

for $V>0$.

where $\alpha$ is the shape parameter. The mean is given by mean $=\alpha$ and $\Gamma(\alpha)$ is the gamma function, given by $\Gamma(\alpha)=\int_{0}^{\infty} t^{\alpha-1} e^{-t} d t$.

\footnotetext{
${ }^{18}$ The second-order condition is satisfied because $R<\mu$ implies g' $>0$.
} 
Let $S=0$. A downward shift in the offer distribution can be characterized by a reduction in $\alpha$. Again, numerical analysis reveals that for all $\alpha>1$, reductions in $\alpha$ result in decreases in the price and increased probability of no sale. ${ }^{19}$

For example, if $\alpha=5$, the mean of the offer distribution is 5 , the optimal price is 3.6 and the probability of no sale is 0.30 . As the market declines, as reflected in a shift of $\alpha$ from 5 to, say 3, the mean falls to 3 , the optimal price falls to 2.3 and the probability of no sale rises to 0.4 .

As before, declines in demand are met by the seller with reductions in the reservation price, but not by an amount large enough to keep the probability of sale the same. Since the probability of sale falls with demand, inventories rise when price declines.

Exponential: Although no counterexamples exist among the standard distributions discussed above, it is clearly possible to construct situations for which it is not true that price and the probability of no sale move in opposite directions. The exponential distribution is one such case. This can be shown analytically as follows.

Let $S=0$. The density function for the exponential is given by

$$
g(V)=\frac{1}{\beta} e^{-\frac{V}{\beta}}
$$

with

$$
G(V)=1-e^{-\frac{V}{\beta}}
$$

From (2),

\footnotetext{
${ }^{19}$ When $\alpha=1$, the gamma becomes the exponential distribution. The result does not hold for this case, as discussed below, and so $\alpha>1$ must be assumed.
} 


$$
\begin{aligned}
R & =\frac{1-\left[1-e^{-\frac{V}{\beta}}\right]}{\frac{1}{\beta} e^{-\frac{V}{\beta}}} \\
& =\beta
\end{aligned}
$$

Substituting $R=\beta$ into $G(V)$, yields $G(R)=1-1 / e$.

Thus, while the reservation price varies with $\beta$, and in fact equals $\beta$, the probability of no sale is constant at $1-1 / e=0.632$. There is no variation in inventories at all if the distribution is exponential. Price changes as a result of demand conditions, but it does so in a way as to hold the sale probability exactly constant.

The results obtained in this section are analogous to those in deterministic markets. In normal circumstances, a decline in demand results in both lower price and lower quantities sold, there are anomalous cases for which that is not true. Strange demand shifts can result in a monopolist choosing to lower his price, but to increase quantity sold. ${ }^{20}$

${ }^{20}$ Here, demand falls from $D 1$ to $D 2$, but the odd nature of demand means that price falls and quantity rises. $\mathrm{MR}$ and $\mathrm{MC}$ refer to marginal revenue and marginal cost, respectively.

Anomalous Case of Price and Quantity

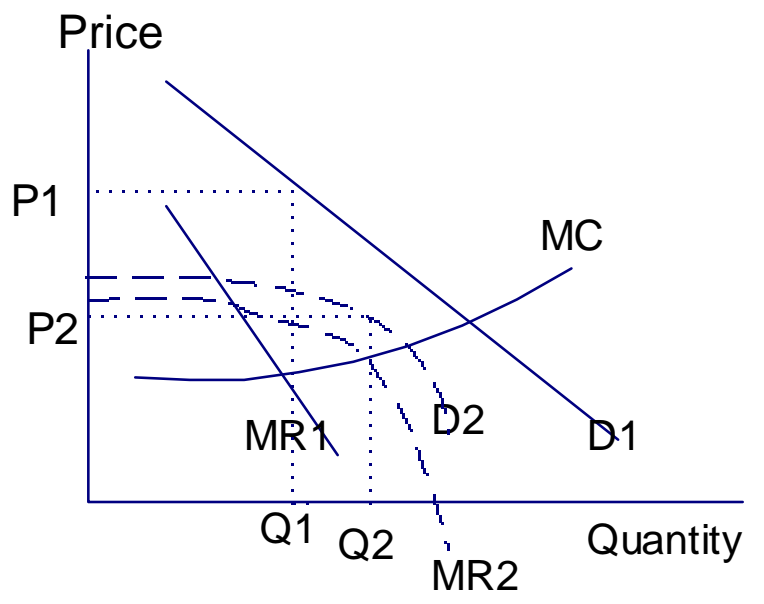


This section shows that in standard cases, prices and inventories move in opposite directions. All is completely rational. The seller understands perfectly that buyers' valuations have fallen and now are below their prior values. There is no stickiness in prices. Prices do fall, but inventories rise simply because it is optimal when the distribution shifts left to lower the price, but not by enough to maintain the same probability of a sale. In the case of standard monopoly in a deterministic environment, a fall in demand results in some decline in price and some decline in quantity sold. In this stochastic environment, the optimal strategy is to lower the price, but also to allow the probability of a sale to fall. So the answer to the puzzle is the traditional one: when demand falls, a price setting seller absorbs some of the decline through lower prices and some through reductions in quantities sold. Here, the seller absorbs some of the decline through lower prices and some through a reduced probability of sale. ${ }^{21}$

\section{Variable Reservation Values}

The result already derived assumed that $S$ did not vary with the distribution of offers. This is analogous to assuming that marginal cost does not change when the demand curve shifts. To see how this assumption affects the key result, it is useful to consider what happens when $S$ is allowed to vary with the $G(V)$ distribution. The question is "what happens to $R$ and the inventories (here, the probability of no sale) when $S$ varies with the shifter in the offer distribution, $k$ ?"

For Inventories to Remain Unchanged, Reservation Value Must Move One-for-One with Demand

\footnotetext{
${ }^{21}$ It is also true that in competition, a decline in demand means falling prices and falling quantities, which results from a move along a positively sloped supply curve.
} 
Do reservation values move enough to keep inventories unchanged? In general, they do not. Consider the displacement $H(V)$ such that $H(V)=G(V+k)$ and $h(V)=g(V+k) \forall k$. There are two parts to the derivation. First, it is shown that if $S$ moves one-for-one with $k$, prices fall and the probability of sale remains unchanged. Second, it will be shown that $S$ will move less than onefor-one with $k$, which results in an increase in inventories with falling prices.

A displacement of the offer distribution by $k$, met with a corresponding change in the reservation value $S$ by $k$, results in lowering the price by exactly the amount of the displacement, $k$. Define the optimum price with the initial distribution, $G(V)$, as $R_{G}$ and the seller valuation as $S_{G}$. From (2)

$$
R_{G}=S_{G}+\frac{1-G\left(R_{G}\right)}{g\left(R_{G}\right)}
$$

so

$$
R_{G}-k=S_{G}-k+\frac{1-G\left(R_{G}\right)}{g\left(R_{G}\right)}
$$

Suppose that $S_{H}=S_{G}-k$ and define $R_{H} \equiv R_{G}-k$. Then,

$$
R_{H}=S_{H}+\frac{1-G\left(R_{H}+k\right)}{g\left(R_{H}+k\right)}
$$

or, because $H(V)=G(V+k)$ and $h(V)=g(V+k) \forall k$,

$$
R_{H}=S_{H}+\frac{1-H\left(R_{H}\right)}{h\left(R_{H}\right)}
$$

which is eq. (2). So the optimal price when $H(V)$ holds is $R_{G}-k$ as long as $S_{H}=S_{G}-k$.

It follows immediately that $H\left(R_{H}\right)=G\left(R_{G}\right)$ because $H(V)=G(V+k)$. Thus, the probability of sale remains constant if the seller's valuation drops by exactly the amount of the displacement. 


\section{Reservation Values Do Not Move One-for-One with the Offer Distribution}

The second part of the argument is that reservation values do not fall one-for-one with the offer distribution. For other goods and services, that they do not move symmetrically is natural. In the case of labor, there is no reason to believe that a worker's value of leisure or even his marginal product at another firm would move identically with the change in the demand for his output at his current firm. For example, a decline in the auto industry that reduces the demand price for an autoworker does not alter the value of his leisure nor does it reduce the amount that he could earn elsewhere by the same amount. Similarly, when demand for a product falls, we assume that the marginal cost curve is unaltered because the general equilibrium effects on costs resulting from shifts in demand in the good being produced are expected to be very small.

The same is true in the case of a new house, where the builder's objective function is different from the buyer's. However, with existing houses, the current and future residents usually want the house for the same purpose - to live in it. Arbitrage between new and existing houses implies that as long as demand declines are not sufficient to prevent new houses from being produced and sold, the marginal seller reservation value is determined by new houses, not by existing houses. Since new house reservation values are determined by construction costs and not demand, this may be sufficient to argue that reservation values are independent of shifts in the offer distribution. But this argument requires competition and the idiosyncrasy among houses weakens this point. So, it is useful to consider how sellers of existing houses reduce their reservation values when demand declines to cover all cases. ${ }^{22}$

\footnotetext{
${ }^{22}$ As long as new and existing houses are close substitutes for one another, we would not expect different market behavior for the two. In particular, there is no reason to expect that the correlation between inventory-to-sales for new houses would be different from that for existing houses. A check of the correlations shows that they are almost identical as expected.
} 
Although the owner/seller's valuation is not independent of the buyer's valuation, in general, forces that shift the offer distribution affect $V$ by more than $S$. The logic is straightforward. In order for there to be a sale, the buyer must value the attributes of the house more than the seller does. Any change in the attributes tends to affect the most those who place the highest value on those attributes. Since the seller already places a relatively low value on the house's attributes, a decline in their levels has less of an absolute effect on the seller's valuation than on the buyer's valuation.

To understand more fully how demand shifts work in housing markets and other markets, it is useful to go behind the distribution of housing price valuations and consider the underlying utility functions from which these may be derived.

Thus, consider a utility function,

$$
U^{i}(A, Y)
$$

where $A$ can be thought of the amount of housing services and $Y$ is all other goods. The superscript $i$ makes clear that individuals can have different utility functions. In the context of the one draw model, a potential buyer is thought of as someone who sees one house that has $A=A_{0}$ with selling price $R$. Let the potential buyer be denoted $b$ and the seller be denoted $s$. For simplicity, assume that the buyer is endowed with $A=0, Y=Y_{b}$. The seller has $A=A_{0}, Y=Y_{s}$.

The seller's reservation value, $S$, is defined such that

$$
U^{s}\left(0, Y_{s}+S\right)=U^{s}\left(A_{0}, Y_{s}\right) .
$$

The buyer's offer value, $V$, is given by

$$
U^{b}\left(0, Y_{b}\right)=U^{b}\left(A_{0}, Y_{b}-V\right) .
$$


From (2), it is clear that $V>S$ for any potential buyer. A fall in the housing market is viewed here as an across-the-board decrease in $A$. For example, housing demand declined in Silicon Valley when the dot-com boom ended around 2000 because the value of a house that was close to Silicon Valley technology firms declined. Similarly, housing demand declined in Texas for the same reason during the 1980 s when oil prices plummeted. ${ }^{23}$ Both can be represented in the services that a given house produces, or as a decline in $A$.

Needed is that whenever $S>V$, it is also true that the inequality condition,

$$
\frac{\partial S}{\partial A}<\frac{\partial V}{\partial A}
$$

holds so that a decline in $A$ shifts the offer by more than it shifts the seller's reservation value.

For marginal changes in $A$,

$$
\frac{\partial S}{\partial A}=\frac{U_{A}^{s}}{U_{Y}^{s}}
$$

and

$$
\frac{\partial V}{\partial A}=\frac{U_{A}^{b}}{U_{Y}^{b}}
$$

As long as the utility functions are well-behaved, $S<V$ implies that the required inequality condition does hold. As a result, a shift in $A$ affects $V$ by more than $S$ (see Appendix B). Here, "well-behaved" means that there are no relative slope reversals so that if the relevant buyer's indifference curve (given by utility level $\left.U^{b}\left(0, Y_{b}\right)\right)$ is steeper than the relevant seller's indifference curve (given by utility level $U^{s}\left(A_{0}, Y_{S}\right)$ ) for $A=0$, then it is steeper for $0 \leq A \leq A_{0}{ }^{24}$

\footnotetext{
${ }^{23}$ An increase in the cost of financing a house as a result of a financial crisis like that which occurred in 2008 is more difficult to capture. That reflects an increase in the difference between what the buyer pays and what the seller receives, which is assumed to be zero in this model.

${ }^{24}$ This is the single-crossing property, applied to utility space.
} 
The conclusion is that under normal circumstances, a decline in demand does not lower $S$ by as much as it does the relevant value of $V$. Consequently, housing prices fall with demand, but not by enough to keep the probability of sale constant.

It is also possible that sales in the housing market reflect changes in supply, rather than changes in demand, where the reservation value, $S$ changes by more than the offer value, $V$. For example, suppose that houses have more than one attribute, like schools and proximity to the opera. Those who currently live in an area may have bought into that area because they cared about a particular attribute that was strongly reflected in houses in that neighborhood, like school quality. If the school quality deteriorated, current owners might suffer a larger loss in utility from the house than the marginal buyer, who might value the house based on other attributes, like proximity to the opera. However, it seems that most factors that affect supply, $S$, more than demand, $V$, are likely to be idiosyncratic, pertaining to a neighborhood rather than to a larger area like a state or the nation as a whole.

\section{Option Value}

In determining $S$, the seller's reservation value, it is useful to remember that many owners have houses that they do not fully own. Most houses are mortgaged at some point during their history and a mortgage gives the owner a put option. By defaulting on the loan, the owner can put part of the liability to the bank at a cost, namely the effect of a default on his credit rating.

When prices fall, the value of the put option goes up for the seller as it is closer to or further in the money. New borrowers, though, pay fair market value for their loan that includes the value of the put option, so there is an asymmetry that grows as prices fall. This is another force 
that keeps $S$ high relative to $V$. It also yields the empirical implication that prices should be "stickier" for houses that have large outstanding mortgages. The owners of these houses should be more reluctant to lower prices because they can put part of the liability to the bank and this option value rises with falling housing prices. Genesove and Mayer (1997) find that owners with higher loan-to-value ratios ask higher prices, have longer expected times on the market, and obtain higher prices conditional on a sale. Their results are consistent with the option-value idea, although they emphasize liquidity, arguing that those with high LTV ratios resulting from a housing bust are less able to place a down payment on a new home if they sell their old one.

\section{Discussion and Extensions}

\section{Heterogeneity is Essential}

The primary result requires and derives from heterogeneity. The intuition is that the seller does not lower the price enough to keep the probability of sale constant because he still hopes that he will find a buyer who values the house at a price higher than the one posted. Without heterogeneity, there can be no inventories (except those that result from random distribution or production disruptions). The only price that a seller can set is the unique value of $V$. Any price above results in the certainty that the house will not sell; any price below discards revenue since the probability of a sale is one at $R=V$.

In competitive markets, no seller ever sets a price that results in a probability of sale less than one so there can be no correlation between prices and inventory. Competitive markets do not display negative correlations between inventories and price changes. In a truly competitive market, goods are homogeneous so no seller ever holds out for a higher price than the market price. Doing 
so would be futile because a rival seller offers an identical good at the market price. The purest case is the stock market, where one share is indistinguishable from the next. The market clears; there are no inventories. The same is true for commodities.

\section{Two Kinds of Inventories}

To investigate this further, initially define two kinds of inventory: "strategic" and "accidental." Strategic inventory is defined as in this paper - a failure to sell because optimal pricing generally allows for uncertain sale. Accidental inventory is that which would result in a competitive industry, simply because the production or distribution processes involve randomness. For example, a small price-taking tomato farmer might be left with tomato inventory when the truck used to take the crop to market breaks down.

Denote strategic inventory in period $t$ as $x_{t}$, accidental inventory in period $t$ as $y_{t}$, and total inventory as $z_{t}$ so

$$
z_{t}=x_{t}+y_{t} \text {. }
$$

Further, denote the price change from $t-1$ to $t$ as $q_{t}$ so

$$
q_{t} \equiv R_{t}-R_{t-1} .
$$

The correlation between $z$ and $q$ is given by

$$
\operatorname{corr}(z, q)=\frac{\sum_{t=1}^{T}\left(z_{t}-\bar{z}\right)\left(q_{t}-\bar{q}\right)}{(T-1) \sigma_{z} \sigma_{q}}
$$

where $\sigma_{z}$ and $\sigma_{q}$ are the standard deviations of $z$ and $q$. 
Because $y_{t}$ is defined as random inventory, it is independent of both $x$ and $q$ so $\operatorname{cov}(x, y)=0$ and $\operatorname{cov}(y, q)=0$. Then (4) can be written as

$$
\operatorname{corr}(z, q)=\frac{\sum_{t=1}^{T}\left(x_{t}-\bar{x}\right)\left(q_{t}-\bar{q}\right)}{(T-1) \sigma_{z} \sigma_{q}}
$$

or

$$
\operatorname{corr}(z, q)=\frac{\sum_{t=1}^{T}\left(x_{t}-\bar{x}\right)\left(q_{t}-\bar{q}\right)}{(T-1) \frac{\sigma_{x}}{\theta} \sigma_{q}}
$$

where $\theta \equiv \frac{\sigma_{x}}{\sigma_{z}}$.

Noting that

$$
\sum_{t=1}^{T} \frac{\left(x_{t}-\bar{x}\right)\left(q_{t}-\bar{q}\right)}{(T-1) \sigma_{x} \sigma_{q}}=\operatorname{corr}(x, q),
$$

eq. (5) can be rewritten as

$$
\operatorname{corr}(z, q)=\theta \operatorname{corr}(x, q) .
$$

Further,

$$
\frac{\partial \operatorname{corr}(z, q)}{\partial \theta}=\operatorname{corr}(x, q)<0 .
$$

The observed correlation between inventories and price changes is decreasing in the proportion of total variance that is strategic rather than accidental. Since the correlation is nonpositive, a decreasing correlation means a correlation that moves from zero toward negative one. At the extreme, when $\theta=1$, from $(6), \operatorname{corr}(z, q)=\operatorname{corr}(x, q)$, because all inventory is strategic. At the other extreme, when $\theta=0$, from $(6), \operatorname{corr}(z, q)=0$, because all inventory is accidental. 
The result yields implications across markets and types of products. First, inventories should be larger in heterogeneous than in homogeneous markets. Other things equal, the total size of the inventory (normalized, perhaps relative to sales) should be smaller in competitive markets than in those with monopoly power because competitive markets have only accidental inventory, whereas those with monopoly power have strategic inventory as well.

Second, the negative relation of price movements to inventories should be more pronounced in heterogeneous markets where monopoly power exists than in homogeneous ones where monopoly power is absent. In the context of the formal model, $\theta$, the ratio of the standard deviation of strategic to the standard deviation of total inventory variance is higher in markets with more monopoly power, which implies that the correlation between the variance in observed inventories and price changes becomes more negative, approaching negative one at the limit.

In the housing context, the situation is closer to competition for homogeneous apartments than for large mansions. As a result, there should be a stronger negative correlation between price movements and inventories for ten-million dollar mansions than for standard condominiums. ${ }^{25}$

\section{Production Smoothing and Inventory}

${ }^{25}$ This does not imply that prices fall more in heterogeneous markets. That depends on a number of factors, including the distribution of demand shocks across different markets (e.g., homogeneous markets may be more or less susceptible to shocks than heterogeneous markets), and the pace at which learning occurs in different markets as discussed in Lazear (1986). That model sought to explain the timing of price changes over time, how the probability of sale varied with the rate of price cuts, and how both varied with the diffusion in underlying priors. As argued in Lazear (1986), mansions, which have thinner markets with higher underlying variance in offers, will exhibit stickier pricing and will have longer time on the market. Noticing the result related to thickness of markets, An (2009) uses a modified version of Lazear (1986), coupled with an instrumental variables approach to investigate the relation of selling price to time on the market. He finds a negative relationship between them. See also Read (1988) and Haurin (1988) for points similar to that in Lazear (1986). Read (1988) in particular emphasizes the relation of reservation price to offers received and notes that this addresses the seemingly paradoxical behavior of sellers to hold on to a property without price reductions sufficient to clear the market. 
Production smoothing may create observed inventory even in some competitive markets. A competitive firm (a farm, for example) with increasing marginal costs might produce and store some of its output during periods of low prices if higher prices were expected later. Even though the seller has no control over price, the buildup of inventory is part of the profit maximizing plan. Production smoothing inventory arises because production is optimally less variable than sales.

There are a number of necessary conditions for there to be production-smoothing inventory. First, the good must be storable. Second, marginal cost must be upward sloping. Third, unless the entire stock of existing goods is measured as inventory, production smoothing does not pertain to goods for resale. Although an existing good can be turned into a future good at storage costs, there is no reason to put it on the market where it registers as an inventory until the good is ready for sale. In the case of housing, all existing homes could be counting as inventory, but measured inventory means houses formally on the market at any given point in time. ${ }^{26}$

When production smoothing occurs, an arbitrage condition sets the maximum difference between futures and spot prices at storage costs since supply in the future can be created by producing today and storing until the future date.

Most of the goods that are the subject of this discussion do not meet these conditions. A comparison between stock markets and housing markets compares primarily resale markets. Owners of existing houses do not put their houses on the market today when prices are anticipated to rise in the future to smooth production. Similarly, stock markets are primarily resale markets, where production smoothing does not arise. Existing shares of stock outstanding are not generally viewed as inventory.

\footnotetext{
${ }^{26}$ As shown below, both theoretically and empirically, resale goods are put on the market procyclically and tend therefore to work counter, rather than in the same direction as strategic inventory.
} 


\section{Houses on the Market}

Economists are used to thinking of everything as being on the market, at least potentially. At the right price, everything is for sale. However, because there are costs of putting goods up for sale and because there are search costs, it is sometimes useful to think of some goods as on the market and others not. That is particularly true in the context of houses, where putting a house up for sale involves costs to the current residents of having their home invaded and viewed by strangers. This is particularly important empirically because the inventory of homes is defined operationally as those homes that are "on the market," not as the total stock of housing.

When does an owner put a house on the market? If there is a cost $c$ to listing the house, then it goes on the market when the expected value of putting the house on the market exceeds the value from retaining the house. Houses go on the market when

$$
G(R)(S-c)+[1-G(R)](R-c)>S
$$

or equivalently when the net gain from putting the house on the market exceeds the costs or

$$
[1-G(R)](R-S)>c \text {. }
$$

The interesting issue for the purposes of this analysis is how changing demand affects the likelihood that a house is put on the market. Suppose the offer distribution shifts left from $G(V)$ to $H(V)$, reflecting a decline in demand. From the earlier derivation, $(R-S)$ falls when the offer distribution shifts left. The earlier results also imply that optimal pricing means a decrease in the probability of sale so $[1-G(R)]$ declines with demand. ${ }^{27}$ Since both terms on the left hand side of (7) decline, (7) is less likely to hold for $H(V)$ than for $G(V)$. Fewer houses are put on the market when demand is low than when demand is high. This is intuitive. A decline in demand makes it

\footnotetext{
${ }^{27}$ Recall that when $S_{H}=S_{G}-k, R_{H}=R_{G}-k$ and $\left(R_{H}-S_{H}\right)=\left(R_{G}-S_{G}\right)$. For $S_{H}>S_{G}-k$, $\left(R_{H}-S_{H}\right)<\left(R_{G}-S_{G}\right)$ and $\left(1-G\left(R_{G}\right)\right)>\left(1-H\left(R_{H}\right)\right)$. As was argued above, $S_{H}>S_{G}-k$.
} 
less likely that the house sells, and if it does sell, the price at which it sells is lower. Consequently, given a fixed cost of putting a house on the market, it cannot be more valuable to do this in periods of low demand than in periods of high demand.

As a consequence, the "on the market" effect tends to work in the opposite direction of the strategic pricing effect as far as total inventories are concerned. The fact that there is a strong negative relation of inventories to price changes, as shown in Figure 1 and in described in Table 1, means that the effect on inventories of strategic pricing outweighs any effect of putting fewer houses on the market during market downturns.

The theoretical prediction that houses are put on the market move procyclically can be checked empirically. An accounting identity is that

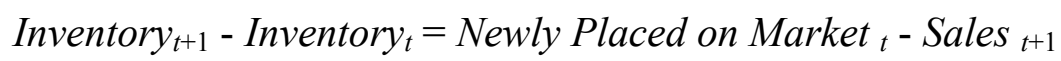

or

$$
\text { Newly Placed on } \text { Market }_{t}=\text { Inventory }_{t+1}-\text { Inventory }_{t}+\text { Sales }_{t+1}
$$

Using (8) and the data that were used for Figure 1 and Table 1, a series of houses newly placed on the market is derived. Table 2 reports the correlation between houses newly put on the market and price changes, both FHFA and S\&P Case Shilller series. As the theory predicts, houses put on the market move procyclically. When prices are rising, more houses are put on the market. During declining markets, fewer houses go on the market. Despite this, inventories rise in declining markets because strategic pricing prevents prices from falling rapidly enough to keep the probability of sale constant. 
Table 2

Correlation of houses newly placed on market with price changes

\begin{tabular}{|c|c|c|}
\hline & Change in FHFA & Change in S\&P Case Shiller \\
\hline Inventory/Sales & 0.41 & 0.37 \\
\hline
\end{tabular}

Monthly data from 1991. 219 observations.

Recap

The empirical observation that inventories rise when prices fall is explained by the fact that the optimal response to a shift in the offer distribution is to change price, but not by enough to keep the probability of sale constant. When demand falls, the seller optimally reduces price, but also allows the probability of a sale to fall. This is complicated by changes in the reservation value that may accompany a change in the offer distribution. But the seller's reservation value does not change as much as that of the offer distribution, which is sufficient to preserve the main result, that inventories and price changes are negatively correlated.

Other Applications

This section uses a variety of data sets for auto, labor and housing markets to provide more evidence on the relation of inventories to price changes. Appendix C provides summary data for all data sets used in this and prior sections. ${ }^{28}$

Auto Sales

${ }^{28}$ Bils and Kahn (2000) document the counter-cyclic movement of the aggregate inventory-to-sales ratio. The theory of this paper would suggest that inventory build-up in recessions would be greater in industries with monopoly power than in those that are purely competitive. A problem is that one would need to control for time to create the product and other non-strategic inventory factors in doing the analysis. 
Autos are like houses in that there are many good substitutes for a given house and there are many good substitutes for a given car. But cars are somewhat idiosyncratic so manufacturers may have a bit of monopoly power. This would imply a negative relationship between inventoryto-sales ratio for cars and changes in prices. $^{29}$

Data were obtained on auto inventories and sales from the Census Bureau. These were paired with the Bureau of Labor Statistics data auto prices. ${ }^{30}$ The data are monthly from 19932009. The correlation between auto inventories and the change in the auto price index is -0.13 with 197 observations. In the aggregate data, which do not differentiate car brands, models, or geographic area, there appears to be a weak negative relation of inventory-to-sales ratio to price changes. It is possible that more detailed data, which disaggregated both prices and inventories, would reveal stronger correlations than the aggregate data, which contain more noise for any given market. The aggregate data camouflage movements from one model type to another, such as the substitution of small cars for larger ones. Price movements and changes in the probability of sale at the aggregate level might be close to zero even when there are dramatic changes in demand from model to model. ${ }^{31}$

\section{Labor Markets}

Labor markets are similar to housing markets. Unemployment in labor markets is analogous to inventories in housing markets. Unemployment reflects labor going unsold. If

${ }^{29}$ Blanchard (1983) examines inventory behavior in autos. Blinder, Lovell and Summers (1981) consider the counter-cyclic nature of inventories, noting autos counter-cycality in particular. Blinder and Maccini (1991) is an overview of evidence and theories on inventories.

${ }^{30}$ Auto inventory and sales data are drawn from the Census Bureau's Monthly Retail Trade Report series. The auto price index data were obtained from the BLS Consumer Price Index series (CPI$\mathrm{U})$.

${ }^{31}$ Copeland, Dunn and Hall (2009) analyze automobile inventories and focus on production smoothing factors in determining inventories. 
workers and firms had symmetric views of the market, one might expect worker to lower their reservation wages by the same amount as firms reduce the wage offer. If they did, no increase in unemployment would result. Declines in the demand for labor result in reductions in reservation wages but not at a rate sufficient to clear the market. This does not imply irrationality or greediness by workers. It simply means that given the alternatives and the positive, even if small, probability of finding a firm that will hire at a better wage, it is utility maximizing to hold out for a better offer than to accept a menial job or to become self-employed at a very low wage. This is the search literature explanation of unemployment.

The data do reveal a negative correlation between unemployment and wage change, but it is very weak. The Depart of Labor, Bureau of Labor Statistics monthly data on employment, wages, and unemployment rates are used from 1964 to 2009. The correlation between unemployment and the monthly change in real earnings is -0.05 with 546 observations.

Again, it is possible that disaggregating the data into specific occupations and sub-markets would yield more correlated series. In particular, it is likely that workers have more monopoly power when they are highly skilled and more specialized. Consider, for example, CEOs versus clerical workers. Clerical workers have little monopoly power and are price-takers. A given CEO has a reputation and the match with any particular firm is more important than for clericals. Match specificity creates heterogeneity in the wage offer distribution and implies that there will be more strategic pricing for CEOs in this market than in the market for clerical workers.

More on Housing 
Housing markets are local and except when large nationally correlated shocks are present, the national data mask what is going on at the local level. ${ }^{32}$ Table 2 summarizes results from a panel data analysis. Existing home sales data at the state level from quarterly data from 1989-2009 were provided by the National Association of Realtors. Unfortunately, no inventory data are available, but higher frequency shifts in the inventory-to-sales ratio are dominated by sales movements. ${ }^{33}$ The dependent variable is the existing home sales level for a particular state market in a given quarter, done with and without taking out trend. ${ }^{34}$ The price variable is the quarterly change in the state FHFA price index. Thus, the unit of analysis is a location year.

The results show that sales, which are now a proxy for the probability of sale, move positively with the change in prices, as expected. When prices are falling, the probability of sale should decline. Table 3 presents the results for regressions (clustered by state and not clustered) of both de-trended and non-de-trended sales on quarterly price changes. The results confirm expectations. ${ }^{35}$ Sales are positively related to price changes in the state panel data.

${ }^{32}$ Glaeser, Gyourko and Saiz (2008) emphasize differences in elasticity of housing supply in explaining price movements across local housing markets. The emphasis in their paper is on bubbles, but their point that price and quantity movements depend on local conditions is what is most relevant here.

${ }^{33}$ At the national level, a regression of $\ln \left(\frac{\text { inventory }}{\text { sales }}\right)$ on $\ln ($ inventory $)$ yields an $\mathrm{R}^{2}$ of 0.33 . A regression of $\ln \left(\frac{\text { inventory }}{\text { sales }}\right)$ on $\ln ($ sales $)$ yields an $\mathrm{R}^{2}$ of 0.56 . Other evidence on the relation of sales to the sales-to-inventory ratio is provided by Falk and Lee (2004) and by Kahn (2000), the latter finding movements in sales without corresponding movements in inventories.

${ }^{34}$ Sales were de-trended by taking out the effects of time and time-squared variables on a state-bystate basis.

${ }^{35}$ Since these data report existing (rather than new) home sales, the price and sales effect cannot be simply the standard supply curve response of more houses being built and therefore sold when demand is expanding. However, one cannot rule out the "on-the-market" effect described earlier from being a part of the explanation because houses placed on the market and demand are positively correlated. 
Table 3

\begin{tabular}{|r|c|c|c|c|}
\hline & \multicolumn{4}{|c|}{ Dependent Variable } \\
\hline & De-trended sales & $\begin{array}{c}\text { De-trended sales } \\
\text { (clustered by state) }\end{array}$ & Sales & $\begin{array}{c}\text { Sales } \\
\text { (clustered by state) }\end{array}$ \\
\hline $\begin{array}{r}\text { Price change } \\
\text { (standard error) }\end{array}$ & $\begin{array}{c}1.87 \\
(0.51)\end{array}$ & $\begin{array}{c}1.87 \\
(0.96)\end{array}$ & $\begin{array}{c}1.91 \\
(0.51)\end{array}$ & $\begin{array}{c}1.91 \\
(0.96)\end{array}$ \\
\hline $\begin{array}{r}\text { Constant } \\
\text { (standard error) }\end{array}$ & $\begin{array}{c}84.64 \\
(1.88)\end{array}$ & $\begin{array}{c}84.64 \\
(13.39)\end{array}$ & $\begin{array}{c}94.81 \\
(1.88)\end{array}$ & $\begin{array}{c}94.81 \\
(13.39)\end{array}$ \\
\hline R-squared & 0.0036 & 0.0036 & 0.0037 & 0.0037 \\
\hline Number of observations & 3703 & 3703 & 3703 & 3703 \\
\hline
\end{tabular}

\section{Conclusion}

Prices and inventories move inversely in some markets. Housing is the most notable case. This is a puzzle because if sellers and buyers updated their beliefs on market conditions in a similar manner, one might expect that sellers would adjust their prices and there would be no price-inventory relationship observed.

The explanation of the negative correlation between prices and inventories is based on rational pricing when sellers face buyers with heterogeneous valuations of their product. Declining demand induces sellers to reduce their prices, but not by enough to keep the probability of sale the same. This is optimal. It is a rational surplus maximizing strategy akin to a monopolist lowering price when demand declines but lowering it by a small enough amount so that quantity sold also falls. A seller understands that the partial price response increases the chances of being stuck with an unsold house. But they willingly take this chance because it pays to hold out in the 
hope that they will encounter a buyer who places a sufficiently high value on their house to buy it at the high price.

The negative correlation between prices and inventories (or probability of no sale) should be observed only in markets where sellers face non-degenerate offer distributions. In purely competitive markets, like a stock market, every seller can sell at the market price. As a result, inventories are predicted to be larger in heterogeneous than in homogeneous markets. Additionally, the negative relation of price movements to inventories should be more pronounced in heterogeneous markets, where monopoly power is greater, than in homogeneous ones, where monopoly power is absent. Auto and labor markets exhibit negative correlations between prices movements and inventories, but the relation is much weaker than in housing markets.

Finally, fewer houses should be put on the market during periods of declining demand, and this prediction is also borne out by the data. 


\section{References}

Akerlof, G. A., and R. Shiller. 2009. Animal Spirits: How Human Psychology Drives the Economy, and Why it Matters for Global Capitalism. Princeton University Press.

Albrecht, J., A. Anderson, E. Smith, and S. Vroman. 2007. "Opportunistic Matching in the Housing Market.” International Economic Review 48, (2): 641-64.

An, Z. 2009. "The Relationship between Selling Price and Time-on-market (TOM): Empirical Evidence in the Submarket of Real Estate Owned (REO) Properties," Manuscript.

Anglin, P. M., R. Rutherford, and T. M. Springer. 2003. "The Trade-off between the Selling Price of Residential Properties and Time-on-the-Market: The Impact of Price Setting." The Journal of Real Estate Finance and Economics 26, (1): 95-111.

Arnold, M. A. 1999. "Search, Bargaining and Optimal Asking Prices.” Real Estate Economics 27, (3): 453-81.

Asabere, P. K., and F. E. Huffman. 1993. "Price Concessions, Time on the Market, and the Actual Sale Price of Homes." The Journal of Real Estate Finance and Economics 6, (2): 167-74.

Banerjee, A. V. 1992. "A Simple Model of Herd Behavior." The Quarterly Journal of Economics 107, (3): 797-817.

Bikhchandani, S., D. Hirshleifer and I. Welch. 1992. "A Theory of Fads, Fashion, Custom, and Cultural Change as Information Cascades." Journal of Political Economy, 100 (5), 9921026.

Bils, M., and J. A. Kahn. 2000. "What Inventory Behavior Tells Us about Business Cycles." The American Economic Review 90, (3): 458-81.

Blanchard, O. J. 1983. "The Production and Inventory Behavior of the American Automobile Industry." The Journal of Political Economy 91, (3): 365-400.

Blinder, A. S., M. C. Lovell, and L. H. Summers. 1981. "Retail Inventory Behavior and Business Fluctuations." Brookings Papers on Economic Activity: 443-520.

Blinder, A. S., and L. J. Maccini. 1991. "Taking Stock: A Critical Assessment of Recent Research on Inventories." The Journal of Economic Perspectives 5, (1): 73-96.

Bulow, J., and P. Klemperer. 1994. "Rational Frenzies and Crashes." The Journal of Political Economy 102, (1): 1-23.

Case, K. E. 2008. "The Central Role of Home Prices in the Current Financial Crisis: How Will the Market Clear?" Brookings Papers on Economic Activity 2, : 161-93.

Case, K. E., and R. J. Shiller. 1989a. "The Behavior of Home Buyers in Boom and post-Boom Markets."

. 1989b. "The Efficiency of the Market for Single-Family Homes." The American Economic Review: 125-37. 
Chen, Y., and R. W. Rosenthal. 1996. "On the Use of Ceiling-Price Commitments by Monopolists." The Rand Journal of Economics: 207-20.

Copeland, A., W. Dunn, and G. Hall. 2009. "Inventories and the Automobile Market." Bureau of Economic Analysis Working Paper.

Falk, B., and B. S. Lee. 2004. "The Inventory-Sales Relationship in the Market for New SingleFamily Homes." Real Estate Economics 32, (4): 645-72.

Fuchs, W., and A. Skrzypacz. 2010. "Bargaining with Arrival of New Traders." Forthcoming, American Economic Review.

Genesove, D., and C. Mayer. 2001. "Loss Aversion and Seller Behavior: Evidence from the Housing Market." Quarterly Journal of Economics 116, (4): 1233-60.

Genesove, D., and C. J. Mayer. 1997. "Equity and Time to Sale in the Real Estate Market." The American Economic Review 87, (3): 255-69.

Glaeser, E. L., J. Gyourko, and A. Saiz. 2008. "Housing Supply and Housing Bubbles.” Journal of Urban Economics.

Glower, M., D. R. Haurin, and P. H. Hendershott. 1998. "Selling Time and Selling Price: The Influence of Seller Motivation." Real Estate Economics 26, (4): 719-21.

Grinblatt, M., S. Titman, and R. Wermers. 1995. "Momentum Investment Strategies, Portfolio Performance, and Herding: A Study of Mutual Fund Behavior." The American Economic Review 85, (5): 1088-105.

Haurin, D. 1988. "The Duration of Marketing Time of Residential Housing." Real Estate Economics 16, (4): 396-410.

Kahn, J. A. 2000. "Explaining the Gap between New Home Sales and Inventories." Current Issues in Economics and Finance 6, (6).

Lazear, E. P. 1986. Retail pricing and clearance sales. The American Economic Review 76, (1): 1432.

Merlo, A., and F. Ortalo-Magné. 2004. "Bargaining over Residential Real Estate: Evidence from England." Journal of Urban Economics 56, (2): 192-216.

Odean, T. 1998. “Are Investors Reluctant to Realize their Losses?” The Journal of Finance 53, (5): 1775-98.

Read, C. 1988. "Price Strategies for Idiosyncratic Goods - The Case of Housing." Real Estate Economics 16, (4): 379-95.

Rosen, S. 1974. "Hedonic Prices and Implicit Markets: Product Differentiation in Pure Competition." Journal of Political Economy 82, (1): 34.

Shiller, R. J. 2006. Irrational Exuberance. Currency.

Tversky, A., and D. Kahneman. 1991. "Loss Aversion in Riskless Choice: A Reference-Dependent Model." The Quarterly Journal of Economics 106, (4) (Nov.): 1039-61. 
Wheaton, W. C. 1990. "Vacancy, Search, and Prices in a Housing Market Matching Model." The Journal of Political Economy 98, (6): 1270-92.

Yavas, A., and S. Yang. 1995. "The Strategic Role of Listing Price in Marketing Real Estate: Theory and Evidence." Real Estate Economics 23, (3): 347-68.

Zuehlke, T. W. 1987. "Duration Dependence in the Housing Market." The Review of Economics and Statistics 69, (4) (Nov.): 701-9. 


\section{Appendix A}

Proof that $R_{H}<R_{G}$ when
a. $H(V)>G(V) \forall V$
b. $g(V) \leq h(V) \forall V$
c. $g^{\prime}, h^{\prime} \geq 0$

Assume the opposite. Then $R_{H}>R_{G}$ which implies that

$$
\frac{1-H\left(R_{H}\right)}{h\left(R_{H}\right)}>\frac{1-G\left(R_{G}\right)}{g\left(R_{G}\right)}
$$

Also, $H(V)>G(V)$ and $R_{H}>R_{G}$ implies that

$$
1-H\left(R_{H}\right)<1-G\left(R_{G}\right)
$$

so that

$$
\frac{1-G\left(R_{G}\right)}{h\left(R_{H}\right)}>\frac{1-G\left(R_{G}\right)}{g\left(R_{G}\right)}
$$

or

$$
h\left(R_{H}\right)<g\left(R_{G}\right)
$$

which is a contradiction because $R_{H}>R_{G}$ and $g$ and $h$ are non-decreasing.

Therefore, $R_{H}<R_{G} \cdot \|$ 


\section{Appendix B}

\section{No Relative Slope Reversals Condition}

To understand this condition, see figure A1. $S<V$ implies the absolute value of the slope of the chord between $M$ and $T$ is less than the absolute value of the slope of the chord between $L$ and $W$. The condition of no relative slope reversals is merely a statement that what holds for relative slopes globally also holds for relative slopes locally. It simply requires that if the slope of $L W$ is greater than the slope of $M T$, then the slope of the indifference curve at $L$ is greater than the slope of the indifference curve at $M$. It rules out situations like those depicted in figure A2, where the indifference curve passing through $L$ is flatter than that through $M$, even though $S>V$. 
Figure A1

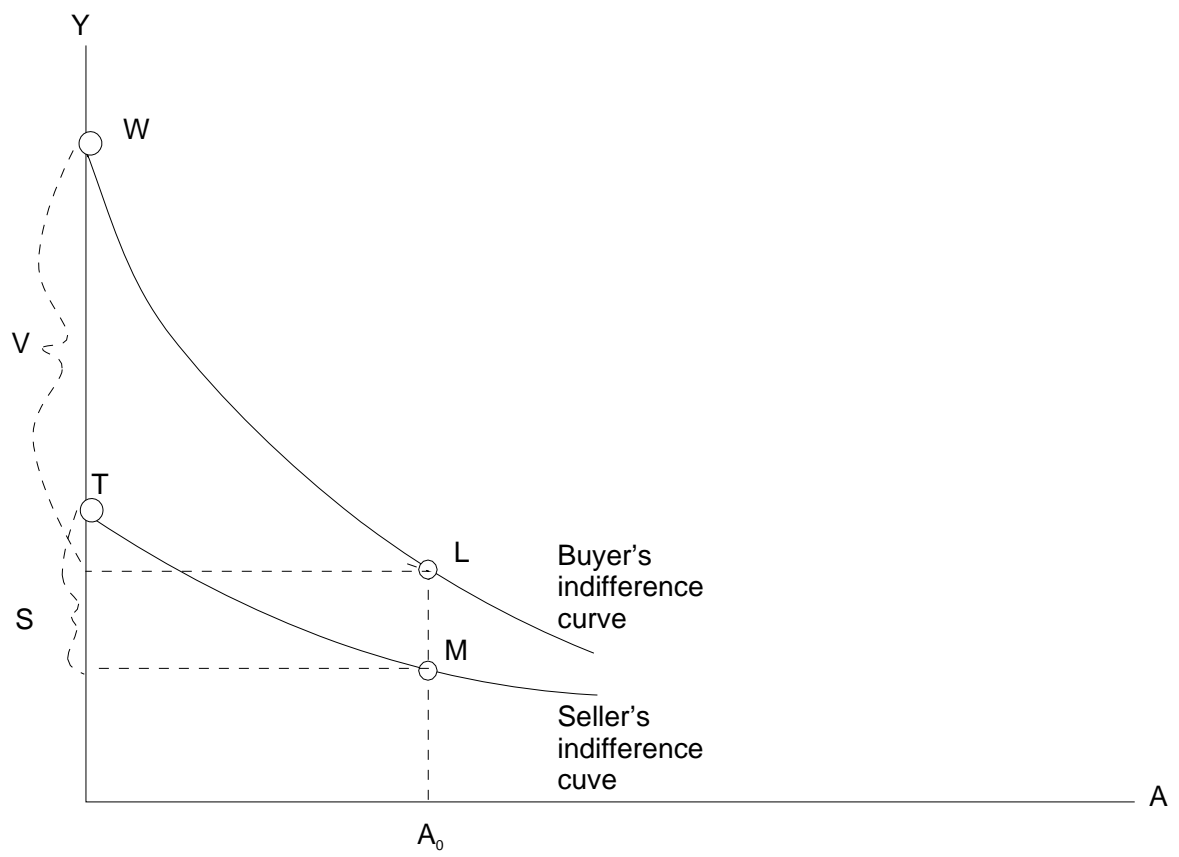


Figure A2

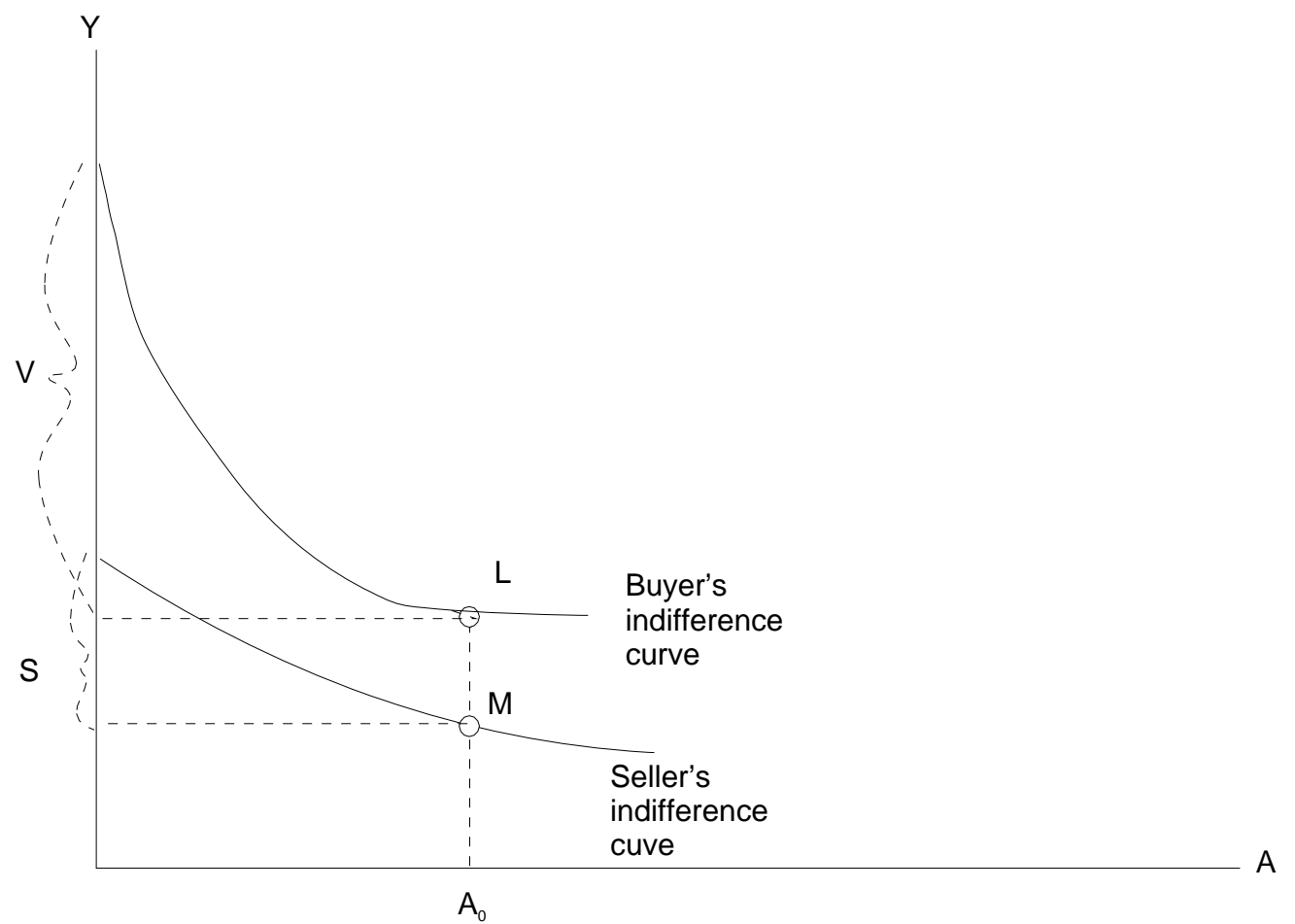


Appendix C

Data Summary Statistics

\begin{tabular}{|c|c|c|c|c|}
\hline Variable & Definition & Mean & Std Dev & $\mathbf{N}$ \\
\hline $\begin{array}{c}\text { National Inventory/Sales } \\
\text { Ratio }\end{array}$ & $\begin{array}{l}\text { The monthly nationwide inventory to } \\
\text { sales ratio for new and existing homes } \\
\text { from the Census Bureau, National } \\
\text { Association of Realtors, and the } \\
\text { Department of Housing and Urban } \\
\text { Development. }\end{array}$ & 6.02 & 1.79 & 220 \\
\hline $\begin{array}{c}\text { Change in FHFA } \\
\text { National Housing Price } \\
\text { Index }\end{array}$ & $\begin{array}{l}\text { The month-to-month change in the } \\
\text { nationwide house price index } \\
\text { compiled by the FHFA. }\end{array}$ & 0.45 & 0.80 & 209 \\
\hline $\begin{array}{l}\text { Change in S\&P Case- } \\
\text { Shiller Metropolitan } \\
\text { Housing Price Index }\end{array}$ & $\begin{array}{l}\text { The month-to-month large } \\
\text { metropolitan area aggregated house } \\
\text { price index from Standard \& Poor's. }\end{array}$ & 0.33 & 1.46 & 209 \\
\hline $\begin{array}{l}\text { State Existing Home } \\
\text { Sales }\end{array}$ & $\begin{array}{l}\text { Quarterly state-level existing home } \\
\text { sales data provided by the National } \\
\text { Association of Realtors (in } \\
\text { thousands). }\end{array}$ & 97.72 & 104.30 & 3703 \\
\hline $\begin{array}{c}\text { De-trended State Existing } \\
\text { Home Sales }\end{array}$ & $\begin{array}{l}\text { De-trended quarterly state-level } \\
\text { existing home sales data provided by } \\
\text { the National Association of Realtors } \\
\text { (in thousands). }\end{array}$ & 87.48 & 104.00 & 3703 \\
\hline $\begin{array}{l}\text { Change in FHFA State } \\
\text { Housing Price Index }\end{array}$ & $\begin{array}{l}\text { Quarterly change in the state FHFA } \\
\text { Housing Price Index. }\end{array}$ & 1.53 & 3.33 & 3703 \\
\hline $\begin{array}{c}\text { National Auto } \\
\text { Inventory/Sales Ratio }\end{array}$ & $\begin{array}{l}\text { The monthly nationwide inventory to } \\
\text { sales ratio for new automobiles from } \\
\text { the Census Bureau. }\end{array}$ & 1.96 & 0.29 & 197 \\
\hline $\begin{array}{l}\text { Change in Auto Price } \\
\text { Index }\end{array}$ & $\begin{array}{l}\text { The month-to-month change in auto } \\
\text { price index from the Bureau of Labor } \\
\text { Statistics. }\end{array}$ & 0.02 & 0.28 & 197 \\
\hline Unemployment Rate & $\begin{array}{l}\text { Monthly unemployment from the } \\
\text { Bureau of Labor Statistics. }\end{array}$ & 5.88 & 1.51 & 546 \\
\hline $\begin{array}{l}\text { Change in Real Hourly } \\
\text { Earnings }\end{array}$ & $\begin{array}{l}\text { Monthly change in real hourly } \\
\text { earnings from the Bureau of Labor } \\
\text { Statistics (1982 Dollars). }\end{array}$ & $\$ 0.001$ & $\$ 0.03$ & 546 \\
\hline
\end{tabular}

